\title{
Phosphoinositide 3-kinase $\gamma$ mediates Jun kinase activation via its lipid-kinase activity
}

\author{
Regina Pietrucha ${ }^{\mathrm{a}}$, Ignacio Rubio ${ }^{\mathrm{a}}$, Matthias P. Wymann ${ }^{\mathrm{b}}$, \\ Reinhard Wetzker ${ }^{\mathrm{a}, *}$ \\ ${ }^{a}$ Institute for Molecular Cell Biology, University Jena, Drackendorfer Straße 1, D-07747 Jena, Germany \\ ${ }^{\mathrm{b}}$ Institute of Biochemistry, University of Fribourg, CH-1700 Fribourg, Switzerland
}

\section{Introduction}

PI3K are multifunctional intracellular proteins, which play a central role in the control of cell functions by extracellular agonists (Vanhaesebroeck et al., 2001). Originally phosphatidylinositol 3,4,5-trisphosphate $\left(\mathrm{PIP}_{3}\right)$ and phosphatidylinositol 3,4-bisphosphate (PI-3,4- $\mathrm{P}_{2}$ ), the products of PI3K lipid-kinase activity, were thought as being the unique mediators of PI3K dependent cellular reactions. Recent data point to additional signaling functions of PI3K protein-kinase activities.

Dhand et al. (1994) described a manganese-dependent phosphorylation of the adapter protein $\mathrm{p} 85$ by the catalytic subunit of $\mathrm{PI} 3 \mathrm{~K} \alpha(\mathrm{p} 110 \alpha)$. These authors demonstrated an inhibitory effect of p85 phosphorylation on PI3K $\alpha$ lipid-kinase activity in vitro. Another tyrosine kinase-linked PI3K, p110 $\delta$, was shown to exhibit in vitro autophosphorylation, which completely down-regulated PI3K $\delta$ lipid-kinase activity (Vanhaesebroeck et al., 1999). The single autophosphorylation site was mapped to Ser1039 at the COOH-terminus of p1108. Antisera specific for phosphorylated Ser1039 revealed a low phosphorylation level of this residue in cell lines. However, stimulation of T cells induced a time-dependent increase in Ser1039 phosphorylation and a concomitant decrease in associated lipid-kinase activity (Vanhaesebroeck et al., 1999).

Autophosphorylation of PI3K $\gamma$ has been demonstrated in the presence of magnesium ions in vitro (Stoyanova et al., 1997). In contrast to the phosphorylation events observed for $\mathrm{PI} 3 \mathrm{~K} \alpha$ and $\mathrm{PI} 3 \mathrm{~K} \delta$ no manganese ions are necessary for the corresponding protein-kinase activity. In addition to its ability to autophosphorylate, PI3K $\gamma$ catalyzes the (trans-) phosphorylation of at least two other signaling proteins: MEK and p101 (Bondev et al., 1999). These reactions exhibit a biphasic

\footnotetext{
*Corresponding author. Institute for Molecular Cell Biology, University Jena, Drackendorfer Straße 1, D-07747 Jena, Germany. Tel.: +49-3641-325650.

E-mail address: reinhard.wetzker@uni-jena.de (R. Wetzker).
} 
response to $G \beta \gamma$ subunits of heterotrimeric $G$ proteins in vitro (Bondev et al., 1999). Whereas low concentrations of $\mathrm{G} \beta \gamma$ induce stimulatory effects on the protein kinase, G $\beta \gamma$ above $200 \mathrm{nM}$ efficiently suppresses auto- and trans-phosphorylation activities. A very recent report did not confirm the down regulation of $\mathrm{PI} 3 \mathrm{~K} \gamma$ protein kinase originally observed above $200 \mathrm{nM}$ G $\beta \gamma$ (Maier et al., 2000).

A first hint for a physiological function of $\mathrm{PI} 3 \mathrm{~K} \gamma$ protein-kinase activity came from recent investigations using functionally defined mutants of PI3K $\gamma$ (Bondeva et al., 1998). Exchange of the predicted lipid-binding site of PI3K $\gamma$ gave rise to mutants with altered or missing lipid-kinase activity. These mutants have been investigated regarding the specific functions of $\mathrm{PI} 3 \mathrm{~K} \gamma$ lipid- and protein-kinase activities during signal transduction to the protein kinases Erk and PKB. The data revealed differential effects of both enzymatic functions on these signaling paths: Whereas a lipid-kinasenegative protein-kinase-only mutant induced full stimulation of Erk after expression in COS-7 cells, the lipid-kinase activity of PI3K $\gamma$ drove the stimulation of PKB.

Recently, we and others have reported activation of the JNK pathway by PI3K $\gamma$ (Lopez-Ilasaca et al., 1998; Go et al., 1998). Using the substrate mutants of PI3K $\gamma$ introduced above, we aimed to explore the role of lipid- and protein-kinase activities for the stimulatory effect of PI3K $\gamma$ on JNK. The results presented here reveal the lipid-kinase activity of PI3K $\gamma$ as an essential mediator of JNK stimulation induced in COS-7 cells.

\section{Materials and methods}

\section{Cell culture and transfection}

COS-7 cells (ATCC) were cultured in Dulbecco's modified Eagle's medium supplemented with $10 \%$ fetal bovine serum. Subconfluent cells were transfected with pcDNA3-HA-JNK or other DNA constructs, using the DEAE-Dextran method (Lopez-Ilasaca et al., 1997). JNK or PKB assays were performed $48 \mathrm{~h}$ after transfection on serum-arrested cells.

\section{DNA constructs}

Constructs of PI3K $\gamma$ exhibiting differential lipid- and protein-kinase activities after expression in COS-7 cells have been described in a recent report (Bondeva et al., 1998). Table 1 summarizes the enzymatic activities of PI3K $\gamma$ wild-type and the substrate mutants KR, cII, cIII and cIV.

Tagged constructs of p101 were created by standard techniques of molecular biology using the pcDNA3 vector.

JNK assays

Serum-starved cells were treated as appropriate and lysed in $(20 \mathrm{mM}$ Hepes pH 7.5 , $1 \mathrm{mM}$ EGTA, $1 \mathrm{mM}$ EDTA, $0.27 \mathrm{M}$ sucrose, $10 \mathrm{mM} \beta$-glycerophosphate, $50 \mathrm{mM}$ 
Table 1

Lipid- and protein-kinase activities of PI3K $\gamma$ wild type (wt) and substrate mutants (from Bondeva et al., 1998)

\begin{tabular}{lllll}
\hline \multicolumn{5}{c}{ Enzymatic activity/substrates in vitro } \\
\cline { 2 - 5 } PI3K $\gamma /$ mutants & Protein kinase & Lipid kinase & & \\
\cline { 2 - 5 } & & PI & PI 4-P & PI 4,5-P2 \\
\hline $\mathrm{wt}$ & + & + & + & + \\
$\mathrm{KR}$ & - & - & - & - \\
$\mathrm{cII}$ & + & + & + & - \\
$\mathrm{cIII}$ & + & + & - & - \\
$\mathrm{cIV}$ & + & - & - & - \\
\hline
\end{tabular}

$\mathrm{NaF}, 5 \mathrm{mM} \mathrm{PP}_{\mathrm{i}}, 1 \% \mathrm{NP}-40,1 \mathrm{mM}$ sodium orthovanadate, $10 \mu \mathrm{g} / \mathrm{ml}$ Leupeptin, Pepstatin A, Antipain, Aprotinin and Benzamidin, $10 \mathrm{mM}$ Pefabloc, $1 \mathrm{mM}$ PMSF, $1 \mathrm{mM}$ DTT). After centrifugation HA-tagged JNK was immunoprecipitated from the clarified supernatants using anti-HA monoclonal antibody (12CA5, Babco) and Gamma-Bind-beads (Pharmacia). Aliquots of the lysates were taken to check the expression levels of transfected genes. Immunoprecipitates were then washed three times with lysis buffer and twice with kinase reaction buffer (12.5 mM MOPS pH 7.5, $12.5 \mathrm{mM} \beta$-glycerophosphate, $7.5 \mathrm{mM} \mathrm{MgCl}_{2}, 0.5 \mathrm{mM}$ EGTA, $0.5 \mathrm{mM} \mathrm{NaF}, 0.5 \mathrm{mM}$ sodium orthovanadate). Reactions were performed in $30 \mu \mathrm{l}$ of kinase reaction buffer containing $2.5 \mu \mathrm{Ci}$ of $\left[\gamma_{-}{ }^{32} \mathrm{P}\right]$-ATP, $10 \mu \mathrm{M}$ unlabeled ATP, $1 \mathrm{mM}$ DTT and $10 \mu \mathrm{g}$ of GST-c-Jun as substrate for $30 \mathrm{~min}$ at $30^{\circ} \mathrm{C}$ on a shaker. Reactions were terminated by addition of $5 \mathrm{x}$ Lämmli buffer, boiled and the samples were transferred to electrophoresis on $8.5 \%$ SDS polyacrylamide gel. Phosphorylated GST-c-Jun was visualized by autoradiography and quantified with a PhosphorImager.

\section{$P K B$ assays}

Serum-starved cells were treated with lysis buffer $(50 \mathrm{mM}$ Tris $\mathrm{pH} 7.5,0.15 \mathrm{mM}$ $\mathrm{NaCl}, 20 \mathrm{mM} \beta$-glycerophosphate, 1\% NP40, 10\% glycerol, $1 \mathrm{mM}$ DTT, $0.1 \mathrm{mM}$ $\mathrm{Na}_{3} \mathrm{VO}_{4}, 25 \mathrm{mM} \mathrm{NaF}, 1 \mu \mathrm{g} / \mathrm{ml}$ Aprotinin, $0.02 \mathrm{mM}$ Leupeptin, $0.018 \mathrm{mM}$ Pepstatin, $1 \mathrm{mM}$ PMSF) (Bondeva et al., 1998). HA-tagged PKB was immunoprecipitated with the anti-HA monoclonal antibody described above. Aliquots of the lysates were analyzed by SDS-PAGE to normalize the amount of HA-PKB. The immunoprecipitates were then washed twice with lysis buffer, once with $0.5 \mathrm{mM} \mathrm{LiCl} / 100 \mathrm{mM}$ Tris $\mathrm{pH} 7.5$ and once with kinase buffer (20 mM Hepes pH 7.5, $10 \mathrm{mM} \mathrm{MgCl}_{2}, 1 \mathrm{mM}$ DTT). Reactions were performed in $50 \mu \mathrm{l}$ volumes of kinase buffer supplemented with $2 \mu \mathrm{Ci}\left[\gamma_{-}{ }^{32} \mathrm{P}\right]$-ATP, $10 \mu \mathrm{M}$ unlabeled ATP and $30 \mu \mathrm{M}$ Crosstide peptide as substrate and incubated for $30 \mathrm{~min}$ at $30^{\circ} \mathrm{C}$ on a thermomixer. Beads were span down and $40 \mu \mathrm{l}$ of the reaction mixtures were spotted onto phosphocellulose paper. The paper pieces were washed four times in $75 \mathrm{mM}$ phosphoric acid and once in acetone. After drying ${ }^{32} \mathrm{P}$ radioactivity was assayed in a scintillation counter. 


\section{Results and discussion}

Heterologous expression of $\mathrm{PI} 3 \mathrm{~K} \gamma$ has been shown to provoke marked stimulation of the protein kinases Erk, JNK and PKB in COS-7 cells (LopezIlasaca et al., 1997, 1998; Murga et al., 1998). In a subsequent study our group demonstrated differential involvement of PI3K $\gamma$ protein- and lipid-kinase activities in the signal transfer to Erk and PKB (Bondeva et al., 1998). Whereas the lipidkinase activity of PI3K $\gamma$ appeared to be essential for the stimulation of PKB a protein-kinase-only mutant sufficed to induce full stimulation of the MAP kinase Erk. A similar approach has now been used to elucidate the specific contributions of PI3K $\gamma$ lipid- and protein-kinase activities to the stimulation of the MAP kinase species JNK in COS-7 cells.

Fig. 1A demonstrates the individual and combined effects of PI3K $\gamma$ and its adaptor protein p101 on JNK activity in these cells. In agreement with our previous report (Lopez-Ilasaca et al., 1998) expression of PI3K $\gamma$ alone induced a weak increase of JNK activity. In some experiments the stimulatory effect was insignificant. Co-expression of PI3K $\gamma$ together with the adaptor p101 caused robust stimulation of JNK. To elucidate the specific functions of PI3K $\gamma$ lipid- and proteinkinase activities we expressed p101 together with the substrate mutants described in Table 1. As shown in Fig. 1B the lipid-kinase-negative protein-kinase-positive mutant cIV was unable to induce JNK activation. Similarly, the cII and cIII mutants, which generate the phosphoinositides PI 3-P (phosphatidylinositol 3phosphate) and/or PI 3,4- $\mathrm{P}_{2}$ (phosphatidylinositol 3,4-bisphosphate), did not affect JNK activity significantly. In conclusion, only wild type PI $3 \mathrm{~K} \gamma$ was effective in JNK stimulation pointing to the lipid-kinase product PIP $_{3}$ (phosphatidylinositol 3,4,5trisphosphate) as an essential element of the regulatory effect on JNK.

The strong potentiation of PI3K $\gamma$-dependent JNK activation by p101 possibly reflected a stimulation of PI3K $\gamma$ lipid-kinase activity by the adapter protein. p101 reportedly amplifies the stimulatory effect of $G \beta \gamma$ subunits of heterotrimeric $G$ proteins on the 3-phosphorylation of phosphoinositides catalyzed by PI3K $\gamma$ (Krugmann et al., 1999; Stephens et al., 1997). Thus the increased stimulation of JNK upon co-expression of p101 is consistent with an essential function of PI3K $\gamma$ lipid-kinase activity and its main product $\mathrm{PIP}_{3}$ for the signal transfer to $\mathrm{JNK}$.

As a prerequisite for efficient phosphorylation of their membrane bound substrate $\mathrm{PIP}_{2}$ PI3K (type I) must associate with the intracellular site of the plasma membrane. Normally translocation and concomitant increase of PI3K lipid-kinase activity occur following receptor stimulation by appropriate agonists. As a consequence, PI3K associate to specific binding partners in the plasma membrane getting access to their lipid substrate $\mathrm{PIP}_{2}$ (for a review see Wymann et al., 2000). Membrane binding and stimulation of PI3K lipid-kinase activity can be artificially induced by the CAAX tag, which contains the $\mathrm{COOH}$-terminal prenylation signal of K-Ras. In contrast to the untagged version, PI3K $\gamma$-CAAX has been shown to trigger significant $\mathrm{PIP}_{3}$ production following expression in COS-7 cells (Bondeva et al., 1998). To further investigate the role of PI3K $\gamma$ lipid-kinase activity in JNK stimulation we expressed PI3K $\gamma$ wild-type and substrate mutants with a CAAX domain at the C-terminus. As 

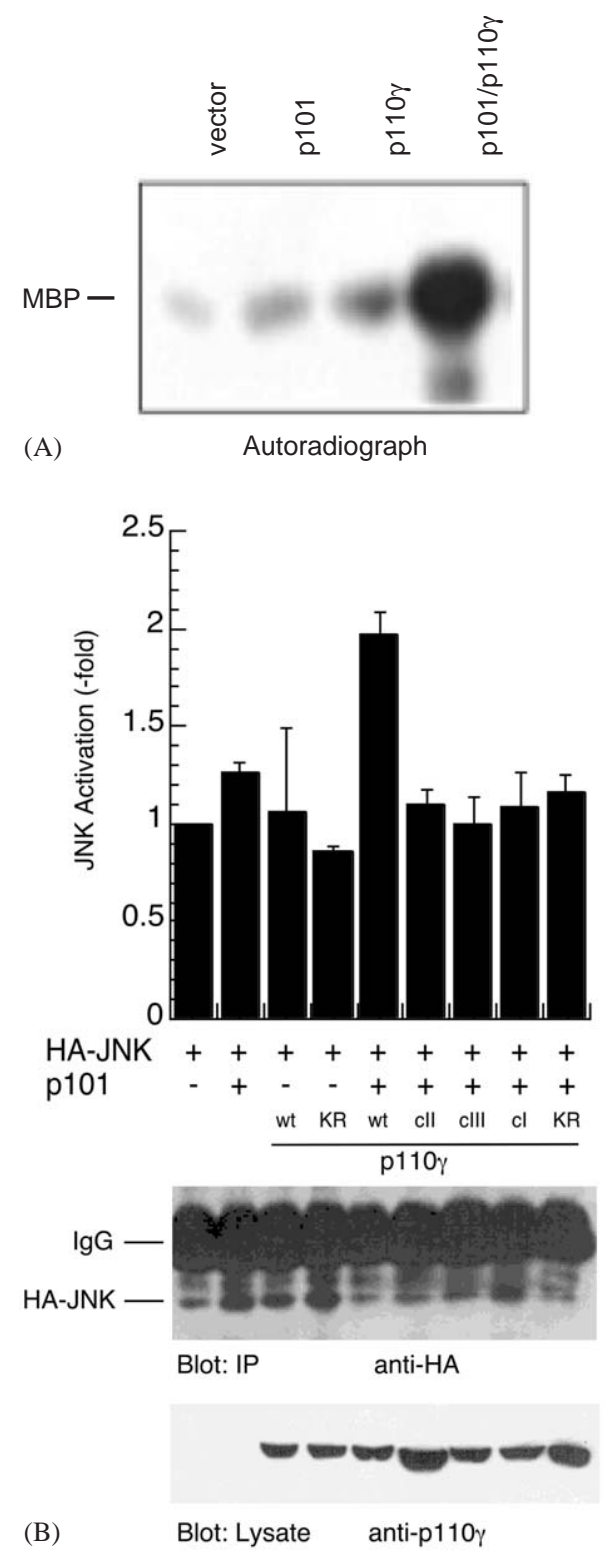

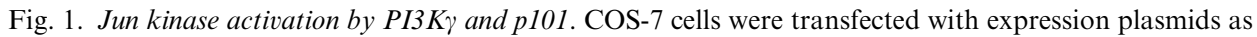
indicated. Two days after transfection cells were lysed and JNK activity was assayed as described under "Methods." (A) Individual and combined effects of PI3K $\gamma$ and p101 on JNK activity. (B) JNK activation induced by PI $3 \mathrm{~K} \gamma$ wild type and substrate mutants in absence or presence of p101.

shown in Fig. 2A PI3K $\gamma$-CAAX and p101 robustly induced JNK activity. Remarkably, the stimulatory effect was observed in the absence of the adaptor protein $\mathrm{p} 101$. In contrast, the CAAX-tagged versions of the PI3K $\gamma$ mutants cII, cIII, 
cIV and KR failed to induce significant stimulation of JNK activity. These data show that neither $\mathrm{PI} 3 \mathrm{~K} \gamma$ protein-kinase activity nor 3-phosphorylation of the phosphoinositides PI and PI 4-P by the substrate mutants were sufficient for JNK stimulation. Taken together, these experiments evidence an essential role of the lipidkinase product $\mathrm{PIP}_{3}$ in $\mathrm{PI} 3 \mathrm{~K} \gamma$ dependent stimulation of JNK.

The comparable degree of JNK stimulation by PI3K $\gamma$ plus p101 or PI3K $\gamma$-CAAX prompted us to conduct parallel experiments on the stimulation of PKB. The lipid kinase constitutively active CAAX-mutant of PI3K $\gamma$ has previously been shown to strongly stimulate PKB (Bondeva et al., 1998). Confirming previous data (Murga et al., 1998) Fig. 2B shows a weak stimulation of PKB by PI3K $\gamma$ wt in the absence of p101 and a stronger effect in cells coexpressing PI3K $\gamma$ and p101. As documented above for JNK activation, the CAAX-mutant of PI3K $\gamma$ stimulated PKB to a similar extent as the PI3K $\gamma / \mathrm{p} 101$ combination. These results indicate that either of the two PI3K species, CAAX-PI3K $\gamma$ or PI3K $\gamma$ plus p101, generates saturating amounts of $\mathrm{PIP}_{3}$ needed for PKB and JNK activation.

The topology of the PI3K $\gamma$ dependent signaling trails to Erk, JNK and PKB remains ill defined. Using specific inhibitors and dominant negative mutants of signaling proteins some candidate elements involved in the signal transfer from PI3K $\gamma$ to the MAP kinases Erk and JNK have been unveiled (Lopez-Ilasaca et al., 1997, 1998). According to those studies, the signal transfer from PI3K $\gamma$ to JNK involved the two small GTPases Ras and Rac. To confirm a possible role of Ras, we compared the impact of dominant-negative N17-Ras on JNK stimulation elicited by p101/PI3K $\gamma$ versus PI3K $\gamma$-CAAX. As shown in Fig. 3 N17-Ras reversed the activation of JNK by either stimulus. Furthermore, N17Ras also blocked JNK activation induced by the CAAX-mutant of a second PI3K species, p110 $\alpha$. Remarkably, N17-Ras reduced basal levels of JNK activity in the absence of any stimulus. These data indicate a prominent function of Ras in the control of JNK activity in COS-7 cells.

The involvement of Ras in PI3K $\gamma$ dependent stimulation of JNK seems to be in conflict with the established role of the small GTPase as an agonist of PI3K. Direct binding and stimulation of PI3K lipid-kinase activity by active Ras has been documented in vitro and in several cellular systems (Rodriguez-Viciana et al., 1994; Rubio et al., 1997; Suire et al., 2002). In contrast the data presented in this report and our recent results on an essential role of Ras for PI3K $\gamma$ dependent stimulation of Erk (Lopez-Ilasaca et al., 1997) indicate a downstream function of Ras during signal transfer from PI3K $\gamma$ to the MAP kinases Erk and JNK. The stimulatory effects of $\mathrm{PI} 3 \mathrm{~K} \gamma$ on Ras activity could be due to a direct association of both signaling proteins and concomitant stabilization of the Ras-GTP conformation (Rubio et al., 1997, 1999). In addition indirect effects of PI3K and their product PIP ${ }_{3}$ on Ras have been reported in numerous cell systems (see Downward, 2003 for review). The tyrosine kinase Src, which has been shown to be sensitive to $\mathrm{PIP}_{3}$, is a candidate mediator for the proposed signal transfer from PI3K to Ras (Lopez-Ilasaca et al., 1997; Toker and Cantley, 1997).

In summary, this report reveals that the lipid-kinase activity of PI3K $\gamma$ rather than its protein-kinase activity mediates stimulation of JNK. The need to further delineate 

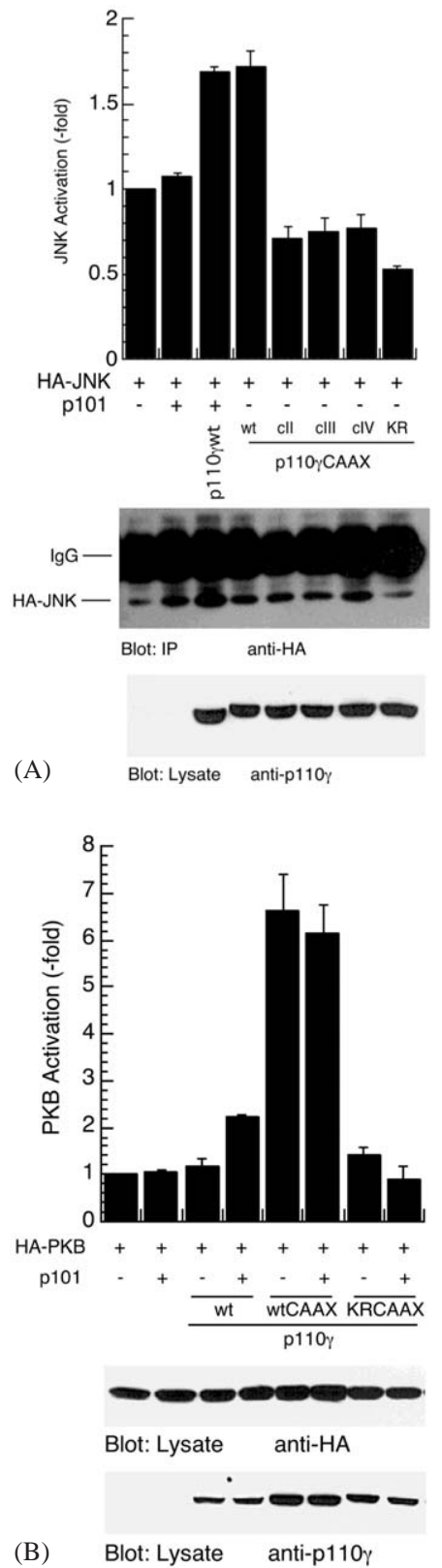

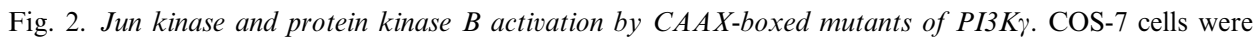
transfected with expression plasmids as indicated. Two days after transfection cells were lysed and JNK and PKB activities were assayed as described under "Methods." (A) Effects of different PI3K $\gamma$ CAAXbox mutants of JNK activity. (B) Regulation of PKB activity by PI3K $\gamma$ wt and kinase negative KR mutant in the presence and absence of p101. 


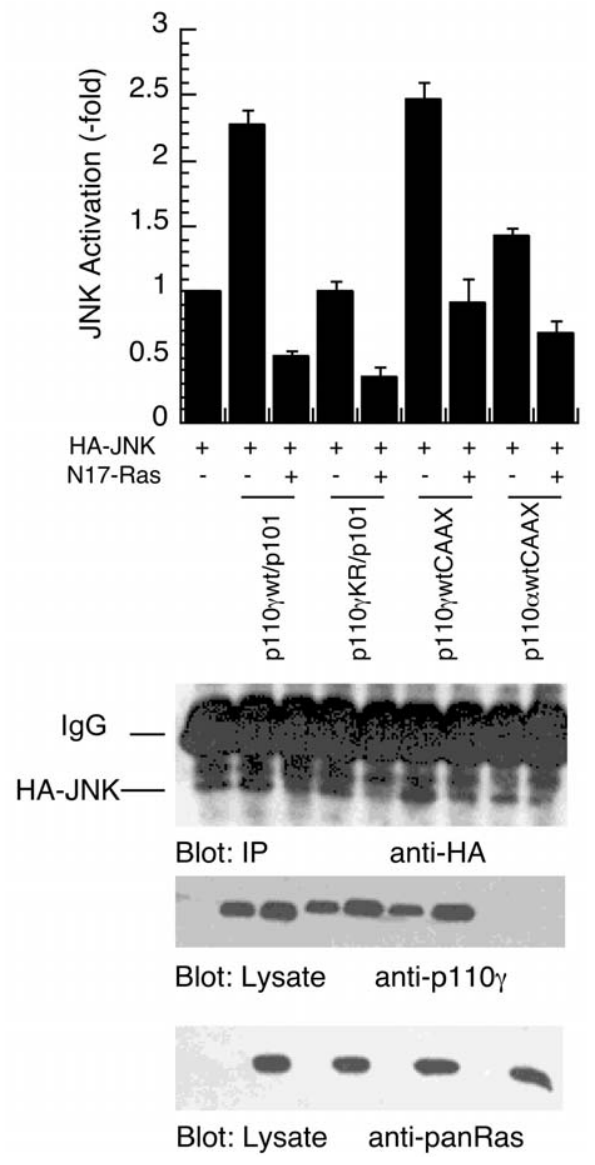

Fig. 3. Inhibition of PI3K $\gamma$-induced JNK activation by dominant negative Ras. COS-7 cells were transfected with expression plasmids as indicated. Stimulation of JNK activity was induced by coexpression of PI3K $\gamma-$ $\mathrm{wt}+\mathrm{p} 101$ or PI3K $\gamma$-CAAX alone. The dominant negative N17 mutant of Ras has been cotransfected as indicated and JNK activity was assayed by using GST-c-jun as substrate. The amount of immunoprecipitated HA-JNK and the expression of p1 $10 \gamma$ and of Ras were assayed with corresponding antibodies.

this pathway is warranted by recent findings pointing to the involvement of PI3K $\gamma$ in shear-stress-induced activation of endothelial cell JNK (Go et al., 1998). Beyond that, the differential contribution of the two enzymatic activities of PI3K $\gamma$ during signal transduction to the MAP kinases Erk and JNK demands further experimentation. We hypothesize that mechanisms exist allowing PI3K $\gamma$ to switch from a protein kinase targeting Erk to a lipid kinase feeding into the JNK or PKB pathways. Accumulating evidence indicates that the adapter protein p101 might fulfill such a switch-like function. Very recently we observed that the cellular expression pattern of $\mathrm{p} 101$ and $\mathrm{PI} 3 \mathrm{~K} \gamma$ does not always overlap, as some cell types, 
e.g., human umbilical vein endothelial cells (HUVEC) do express PI3K $\gamma$ but not p101 (R. Wetzker, unpublished observations). It is attractive to speculate that in HUVEC cells, PI3K $\gamma$ should preferentially function as a protein kinase and, consequently, as an Erk activator and that this pattern should change upon forced expression of $\mathrm{p} 101$.

\section{Summary}

Phosphoinositide 3-kinases (PI3K) are bifunctional enzymes expressing lipid- and protein-kinase activities. PI3K lipid kinase is involved in the control of cell motility, survival and other cellular reactions. Recent data point to specific signaling functions of PI3K protein-kinase activities. The PI3K species $\gamma$ has been shown to stimulate major signaling paths to the protein kinases Erk, JNK and PKB, in COS-7 cells. The present work was aimed to decipher the signaling reactions involved in the control of JNK activity by PI3K $\gamma$. Using functionally defined mutants we demonstrate an essential role of PI3K $\gamma$ lipid-kinase activity for JNK stimulation. Together with recent findings these data evidence differential effects of $\mathrm{PI} 3 \mathrm{~K} \gamma$ protein- and lipidkinase activities on Erk, JNK and PKB signaling pathways.

\section{Acknowledgements}

We thank Dr Len Stephens for providing p101 cDNA. This work was supported by grants from the Deutsche Forschungsgemeinschaft (SFB 604) and the European Union.

\section{References}

Bondeva T, Pirola L, Bulgarelli-Leva G, Rubio I, Wetzker R, Wymann MP. Bifurcation of lipid and protein kinase signals of PI3K $\gamma$ to the protein kinases PKB and MAPK. Science 1998;282(5387):293-6.

Bondev A, Rubio I, Wetzker R. Differential regulation of lipid and protein kinase activities of phosphoinositide 3-kinase gamma in vitro. Biol Chem 1999;380(11):1337-40.

Dhand R, Hiles I, Panayotou G, Roche S, Fry MJ, Gout I, Totty NF, Truong O, Vicendo P, Yonezawa $\mathrm{K}$, et al. PI 3-kinase is a dual specificity enzyme: autoregulation by an intrinsic protein-serine kinase activity. EMBO J 1994;13(3):522-33.

Downward J. Targeting RAS signaling pathways in cancer therapy. Nat Rev Cancer 2003;3(1):11-22 [Review].

Go YM, Park H, Maland MC, Darley-Usmar VM, Stoyanov B, Wetzker R, Jo H. Phosphatidylinositol 3-kinase $\gamma$ mediates shear stress-dependent activation of JNK in endothelial cells. Am J Physiol 1998;275(5 Part 2):H1898-904.

Krugmann S, Hawkins PT, Pryer N, Braselmann S. Characterizing the interactions between the two subunits of the $\mathrm{p} 101 / \mathrm{p} 110 \gamma$ phosphoinositide 3-kinase and their role in the activation of this enzyme by G $\beta \gamma$ subunits. J Biol Chem 1999;274(24):17152-8.

Lopez-Ilasaca M, Crespo P, Pellici PG, Gutkind JS, Wetzker R. Linkage of G protein-coupled receptors to the MAPK signaling pathway through PI 3-kinase $\gamma$. Science 1997;275(5298):394-7. 
Lopez-Ilasaca M, Gutkind JS, Wetzker R. Phosphoinositide 3-kinase $\gamma$ is a mediator of G $\beta \gamma$-dependent Jun kinase activation. J Biol Chem 1998;273(5):2505-8.

Maier U, Babich A, Macrez N, Leopoldt D, Gierschik P, Illenberger D, Nurnberg B. G $\beta_{5} \gamma_{2}$ is a highly selective activator of phospholipid-dependent enzymes. J Biol Chem 2000;275(18):13746-54.

Murga C, Laguinge L, Wetzker R, Cuadrado A, Gutkind JS. Activation of Akt/protein kinase B by G protein-coupled receptors. A role for $\alpha$ and $\beta \gamma$ subunits of heterotrimeric $\mathrm{G}$ proteins acting through phosphatidylinositol-3-OH kinase $\gamma$. J Biol Chem 1998;273(30):19080-5.

Rodriguez-Viciana P, Warne PH, Dhand R, Vanhaesebroeck B, Gout I, Fry MJ, Waterfield MD, Downward J. Phosphatidylinositol-3-OH kinase as a direct target of Ras. Nature 1994;370(6490): $527-32$.

Rubio I, Rodriguez-Viciana P, Downward J, Wetzker R. Interaction of Ras with phosphoinositide 3-kinase $\gamma$. Biochem J 1997;326(Part 3):891-5.

Rubio I, Wittig U, Meyer C, Heinze R, Kadereit D, Waldmann H, Downward J, Wetzker R. Farnesylation of Ras is important for the interaction with phosphoinositide 3-kinase $\gamma$. Eur J Biochem 1999;266(1):70-82.

Stephens LR, Eguinoa A, Erdjument-Bromage H, Lui M, Cooke F, Coadwell J, Smrcka AS, Thelen M, Cadwallader K, Tempst P, Hawkins PT. The G $\beta \gamma$ sensitivity of a PI3K is dependent upon a tightly associated adaptor, p101. Cell 1997;89(1):105-14.

Stoyanova S, Bulgarelli-Leva G, Kirsch C, Hanck T, Klinger R, Wetzker R, Wymann MP. Lipid kinase and protein kinase activities of G-protein-coupled phosphoinositide 3-kinase $\gamma$ : structure-activity analysis and interactions with wortmannin. Biochem J 1997;324(Part 2):489-95.

Suire S, Hawkins P, Stephens L. Activation of phosphoinositide 3-kinase by Ras. Curr Biol 2002;12(13):1068-75.

Toker A, Cantley LC. Signalling through the lipid products of phosphoinositide-3-OH kinase. Nature 1997;387(6634):673-6.

Vanhaesebroeck B, Higashi K, Raven C, Welham M, Anderson S, Brennan P, Ward SG, Waterfield MD. Autophosphorylation of $110 \delta$ phosphoinositide 3-kinase: a new paradigm for the regulation of lipid kinases in vitro and in vivo. EMBO J 1999;18(5):1292-302.

Vanhaesebroeck B, Leevers SJ, Ahmadi K, Timms J, Katso R, Driscoll PC, Woscholski R, Parker PJ, Waterfield MD. Synthesis and function of 3-phosphorylated inositol lipids. Annu Rev Biochem 2001;70:535-602.

Wymann MP, Sozzani S, Altruda F, Mantovani A, Hirsch E. Lipids on the move: phosphoinositide 3-kinases in leukocyte function. Immunol Today 2000;21(6):260-4. 